\title{
An Ultrawideband Monopole Fractal Antenna with Coplanar Waveguide Feed
}

\author{
Muhammad Naeem Iqbal, Hamood-Ur-Rahman, and Syeda Fizzah Jilani \\ Department of Electrical Engineering, College of Electrical and Mechanical Engineering, \\ National University of Sciences and Technology (NUST), Rawalpindi 46000, Pakistan \\ Correspondence should be addressed to Muhammad Naeem Iqbal; naeem27@ee.ceme.edu.pk
}

Received 8 October 2013; Revised 5 February 2014; Accepted 25 February 2014; Published 25 March 2014

Academic Editor: Xiaoying Zhao

Copyright (C) 2014 Muhammad Naeem Iqbal et al. This is an open access article distributed under the Creative Commons Attribution License, which permits unrestricted use, distribution, and reproduction in any medium, provided the original work is properly cited.

\begin{abstract}
A novel ultrawideband fractal antenna in monopole configuration is proposed. Wideband behavior and miniaturization is achieved using concentric heptagonal array structure. Coplanar waveguide is used to feed fractal antenna. Base shape for fractal antenna is heptagonal geometry. Final fractal shape is achieved by performing four base shape iterations. FR4 substrate is used for antenna fabrication. Simulated and measured results comparison shows a bandwidth of $7 \mathrm{GHz}$ with $9 \mathrm{GHz}$ center frequency. Radiation pattern of monopole fractal antenna is omni directional. Fundamental purpose of designing and fabricating UWB fractal antenna is its application in body area networks for remote patient health monitoring. Its application also includes $\mathrm{C}$ and $\mathrm{X}$ band frequencies.
\end{abstract}

\section{Introduction}

Vast majority of modern wireless applications require compact, wideband, low cost, and low profile antennas [1-4]. Decrease in antenna efficiency along with size reduction is a major drawback [5]. Fractal antennas present solution for designing compact and wideband antennas. Characteristics like long electrical lengths, self-similarity, and jagged shapes of fractal geometry provide miniaturization, effective radiation, and multiband behavior [6-9]. Available fractal geometries for wideband applications are Sierpinski, Koch, Minkowski, and Pythagorean tree [10-13].

Patch antennas have been widely used in wireless applications due to their low cost and profile but their main disadvantage is narrow impedance bandwidth $[14,15]$. Coplanar waveguide feed provides wideband impedance matching, thermal cooling, structural strength, good isolation, and low complexity of design. Integration of fractal antenna with CPW feed results in wideband impedance matching.

Advantages of ultrawideband technology are low interference, security, high data rates, and immunity to multipath interference [16]. Antenna for UWB applications requires wideband impedance matching characteristic and compactness [17] as shown in wideband planar monopole design [18]. Ultrawideband communication system applications require impedance bandwidth to be 20 percent of center frequency or $500 \mathrm{MHz}$ whichever is lesser [19].

Various polygonal shape antennas are designed to find desired polygonal geometry with wideband property. Proposed solution with heptagonal fractal antenna gives desired performance. Heptagonal base shape is iterated to obtain concentric array structure. Scaled versions of base shape are used to perform four iterations. In order to achieve the ultrawide bandwidth, designed antenna should be size proportional to the frequencies it covers. Concentric array structures are incorporated as the antenna lengths vary in loops. Outer most array has the largest size covering the lower side of frequency band, whereas inner arrays cover the higher frequencies. Bandwidth increases with the increase in the fractal arrays till the third iteration. Fourth and successive iterations give no significant improvement in bandwidth.

Geometry shows reduction in size and desired antenna parameters. Proposed antenna is light weight, compact, wideband with $7 \mathrm{GHz}$ bandwidth and has easy installation for 
UWB applications. Motivation for this research is in the fields of body area networks. However, other application areas also include $\mathrm{C}$ and $\mathrm{X}$ band frequencies.

\section{Antenna Design}

One of the limitations of conventional microstrip antennas is narrow bandwidth particularly for antenna size that is less than $\lambda / 2$. Miniaturization and ultrawide bandwidth can both be achieved simultaneously using fractal concept. Various fractal geometries like Sierpinski, Koch, Minkowski, and Pythagorean tree already have been extensively explored. Polygonal shapes [20] like triangular, rectangular, pentagonal, and hexagonal $[21,22]$ have also been used in different applications. Heptagonal shape is chosen due to its novelty in fractal designs and to study heptagonal fractal monopole antenna characteristics as compared to conventional antennas. Merely heptagonal design cannot produce ultrawide band results. This is achieved using recursive concentric design.

Heptagonal base shape is iterated to get concentric structure. Base shape is a grid of equilateral triangles. Number of elements in grid to make base shape is seven. Base shape or generating array is considered to have a scale factor of 1. Recursive scaled versions of initial generating array are integrated with base shape. This results in a sequence of concentric self-similar arrays as shown in Figure 1. Nested arrays are formed by integrating scaled versions of base shape. Copper area on top also increases with number of iterations but overall area of proposed antenna is still much lesser than planar polygonal geometry.

Array factor in general is expressed as [23]

$$
\operatorname{AF}_{p}(\psi)=\prod_{p=1}^{P} \mathrm{GA}\left(\delta^{p-1} \psi\right),
$$

where $P$ is scale value. Generating array factor for heptagonal concentric arrays is given as [19]

$$
\mathrm{GA}(\theta, \phi)=\sum_{m=1}^{M} \sum_{n=1}^{N_{m}} I_{m n} e^{j \psi_{m n}(\theta, \phi)}
$$

where

$$
\psi_{m n}(\theta, \phi)=k r_{m} \sin \theta \cos \left(\phi-\phi_{m n}\right)+\alpha_{m n},
$$

where $k=2 \pi / \lambda, m=$ number of concentric rings, $n_{m}=$ number of elements on $m$ th ring, $r_{m}=$ radius of $m$ th ring, $I_{m n}$ $=$ excitation current amplitude of $n$th element on $m$ th ring located at $\Phi=\Phi_{m n}$, and $\alpha_{m n}=$ excitation current phase of $n$th element on $m$ th ring located at $\Phi=\Phi_{m n}$. Array scale values and number of concentric rings are varied. Design and fabrication of antenna is carried out on FR4 substrate with 4.4 permittivity.

Substrate and copper thickness are $1.6 \mathrm{~mm}$ and $17 \mu \mathrm{m}$, respectively. Length and width of substrate are $20 \mathrm{~mm}$ and $25 \mathrm{~mm}$, respectively. Proposed monopole CPW fed antenna is shown in Figure 2.
TABLE 1: Fractal antenna dimensions.

\begin{tabular}{lc}
\hline Fractal antenna dimensions & Values $(\mathrm{mm})$ \\
\hline Finite ground width & 10.25 \\
Center conductor width & 3.7 \\
Heptagonal side length & 6.8 \\
Inner side length & 3.6 \\
Substrate length & 20 \\
Substrate width & 25 \\
CPW gap & 1.3 \\
\hline
\end{tabular}

Dimensions of proposed monopole CPW fed antenna are given in Table 1.

Center frequency for fractal antenna design is $9 \mathrm{GHz}$. Fabricated prototype fractal antenna is shown in Figure 3.

Antenna fabrication is carried out on FR4 substrate with LPKF machine. Single sided PCB is used to fabricate fractal antenna with array patterns. Female SMA connector with $50 \Omega$ impedance is used.

\section{Simulated and Measured Results}

Simulation for antenna parameter analysis is performed in HFSS. Main antenna parameters which are focused in this analysis are impedance matching, $S_{11}$, VSWR, directivity, gain, radiation pattern, and efficiency. Frequency range for this analysis is 5 to $15 \mathrm{GHz}$.

CPW gap value is obtained from conformal mapping technique in quasistatic analysis. Parametric analysis in terms of CPW gap variation is performed to achieve $50 \Omega$ input impedance for proper matching. Port impedance plots for two port network of CPW after parametric analysis is shown in Figure 4. Solution frequency range is from 5 to $12 \mathrm{GHz}$. At $1.3 \mathrm{~mm}$ CPW gap $50 \Omega$ impedance matching is achieved. Gap variation for 0.1 to $1.5 \mathrm{~mm}$ in steps of $0.1 \mathrm{~mm}$ is performed. Return loss plot depicts proper impedance matching in desired frequency range.

Comparison between $S_{11}$ simulated and measured plots is also depicted in Figure 5. $S_{11}$ values in $7 \mathrm{GHz}$ frequency range are below $-10 \mathrm{~dB}$ as shown in Figure 5 . This results in wideband impedance matching resulting in lower losses. Major difference between simulated and measured $S_{11}$ plots is due to over etching issue during fabrication by LPKF machine. Results can be improved using chemical etching technique.

Vector plot of surface current for antenna on FR4 is shown in Figure 6. Overall antenna length is comparable to half of wavelength at $10 \mathrm{GHz}$. Due to this, phase reversals are not seen in surface current vector plots. This results in constructive interference of radiating waves, and radiated electromagnetic waves propagate in desired direction. Unwanted lobes will appear if length of antenna is increased. This will cause change in desired omnidirectional pattern.

Simulated radiation pattern plots with antenna orientation of Figure 3 are shown in Figures 7, 8, 9, and 10. These radiation pattern plots show that radiated electric field has doughnut shape over frequency range of $7 \mathrm{GHz}$. 


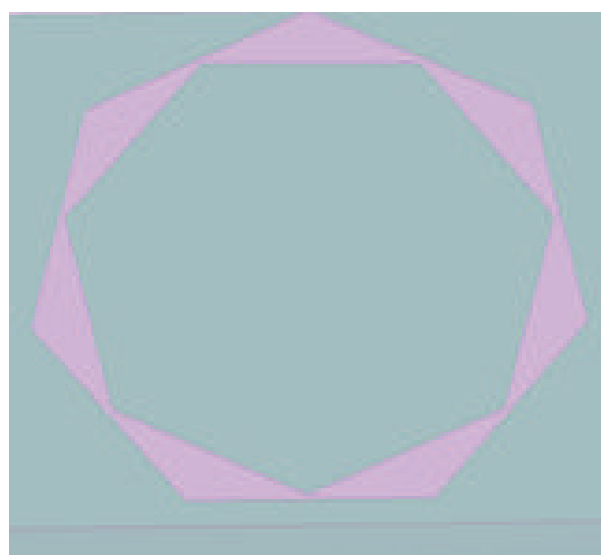

(a)

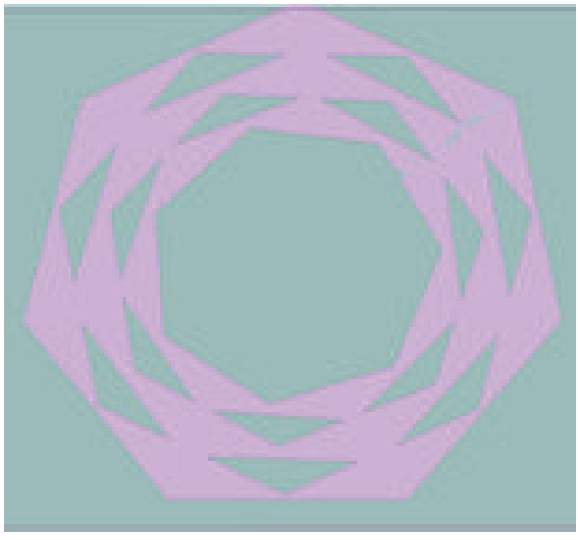

(c)

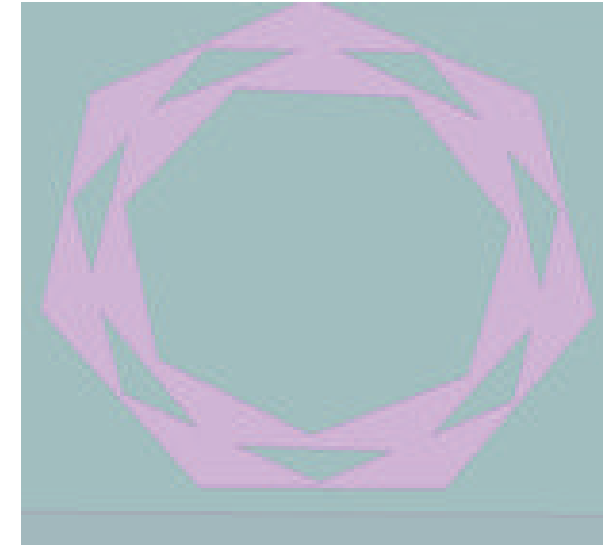

(b)

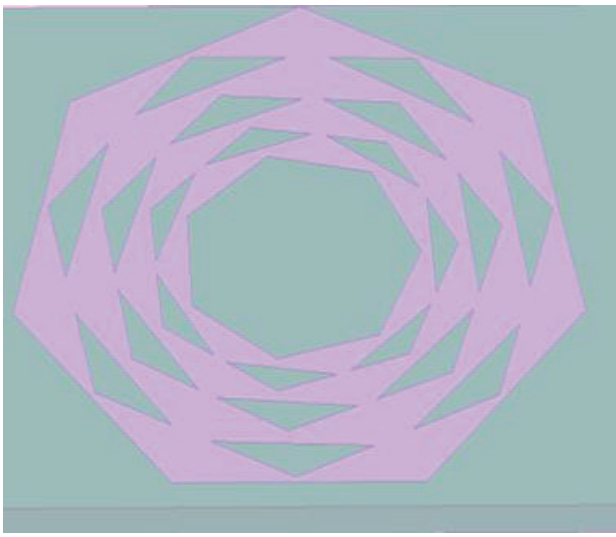

(d)

FIgURE 1: Heptagonal arrays: (a) base shape, (b) 1st iteration, (c) 2nd iteration, (d) 3rd iteration.

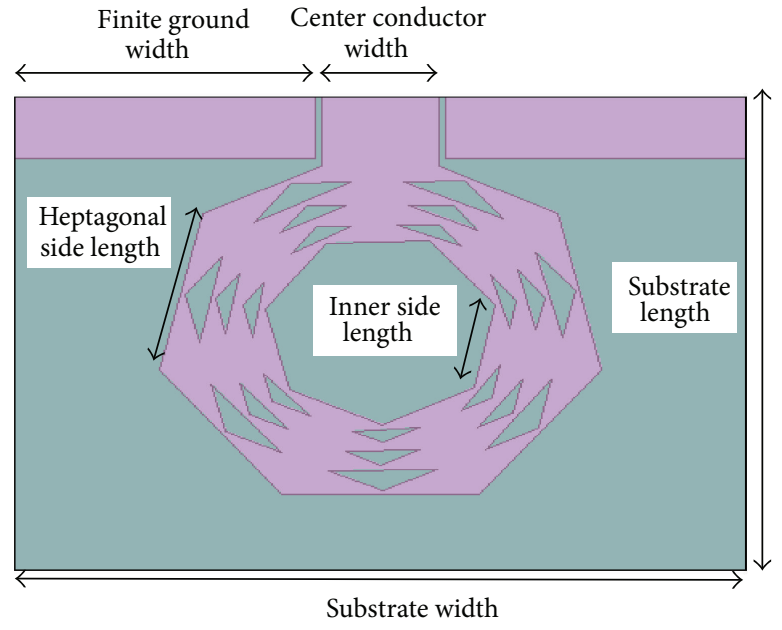

Figure 2: Monopole fractal antenna structure.

Radiation patterns shown in Figures 7, 8, 9, and 10 are plotted for 6, 8, 10, and $12 \mathrm{GHz}$ frequencies, respectively. Radiation pattern remains omnidirectional over a wide frequency range of $7 \mathrm{GHz}$.

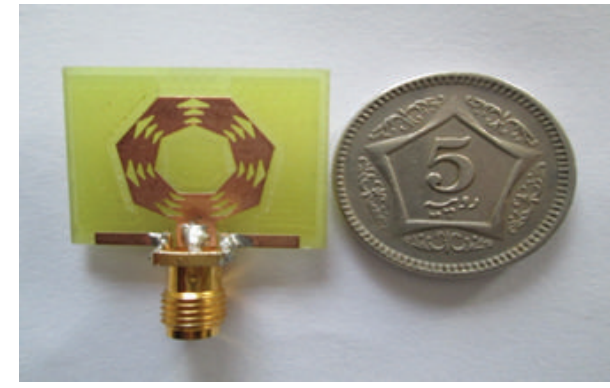

FIGURE 3: Fabricated prototype antenna on FR4 substrate.

At the extreme ends of operating frequency bandwidth of proposed antenna, omnidirectional pattern seems to be shifting. Omnidirectional doughnut shape of radiated electric field lies along $y z$-plane or around $x$-axis. Radiated electric field doughnut gets tilted towards positive $x$-axis when frequency approaches $12 \mathrm{GHz}$ as shown in Figure 10. Antenna use is feasible over $7 \mathrm{GHz}$ bandwidth as shape of radiated electric field is omnidirectional.

Horizontal, vertical cuts, and 3D plots of measured radiation pattern at $8 \mathrm{GHz}$ are shown in Figures 11, 12, and 13 , respectively. 


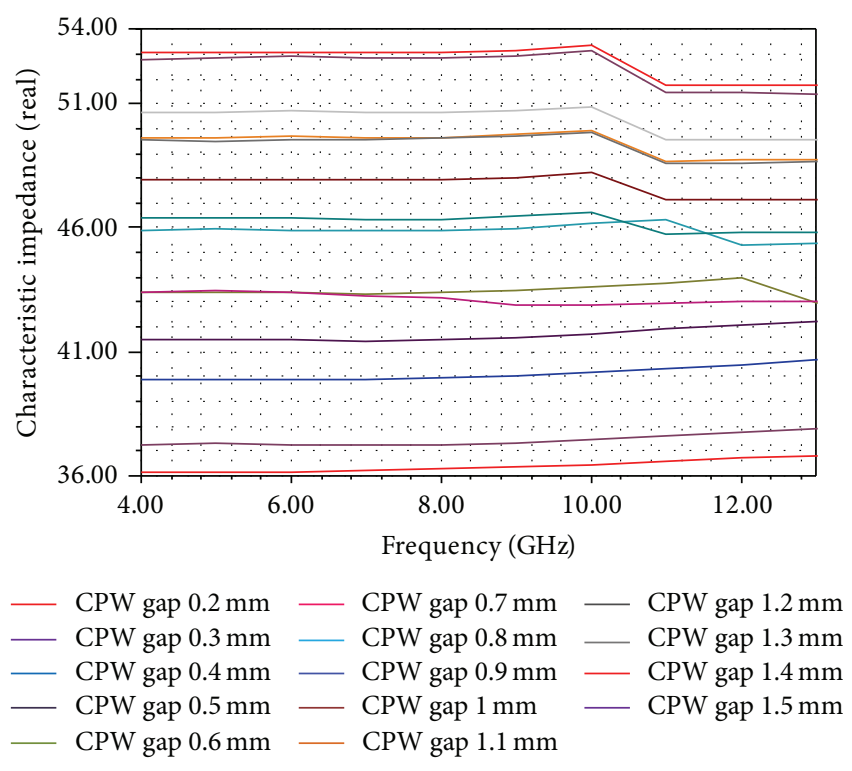

FIgURE 4: Port impedance (real) plots for CPW gap variation.

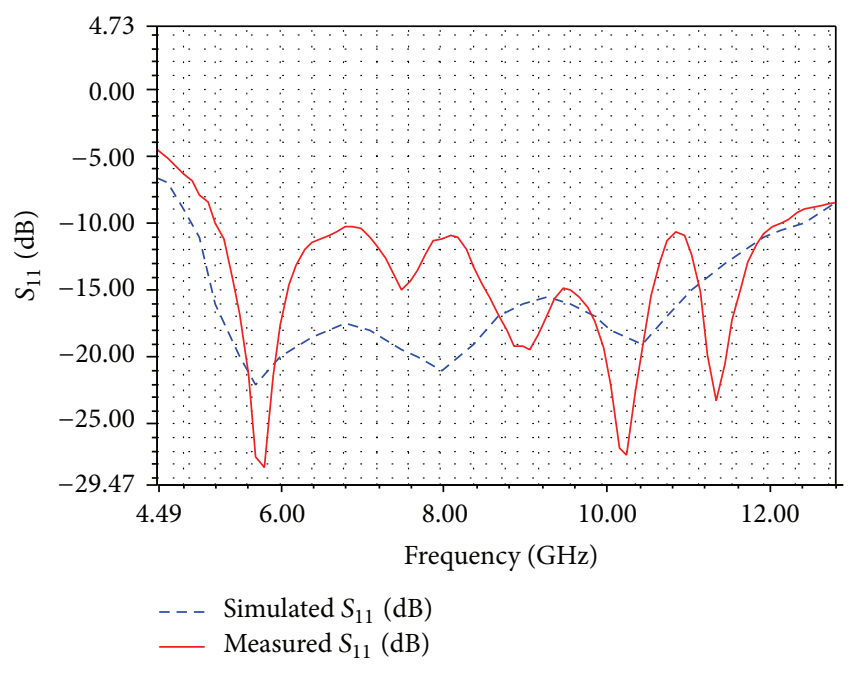

FIGURE 5: $S_{11}(\mathrm{~dB})$ simulated and measured plot.

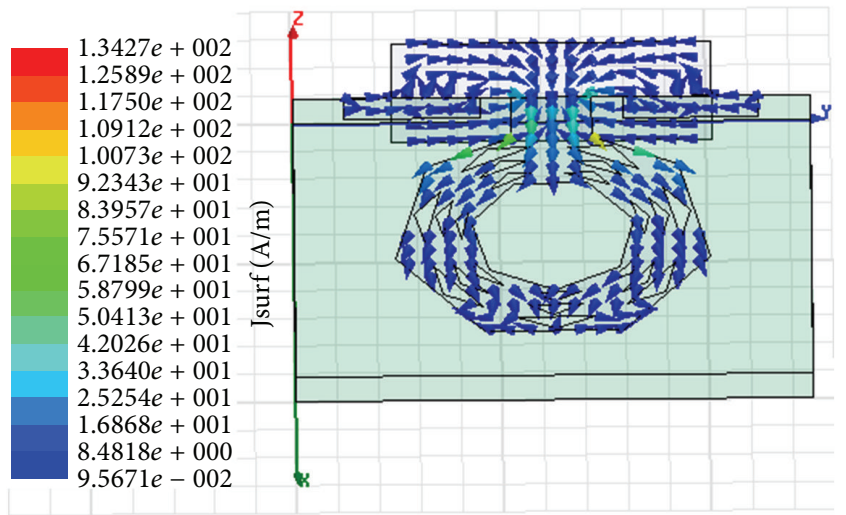

FIGURE 6: Vector surface current plot for FR4 antenna at $9 \mathrm{GHz}$.

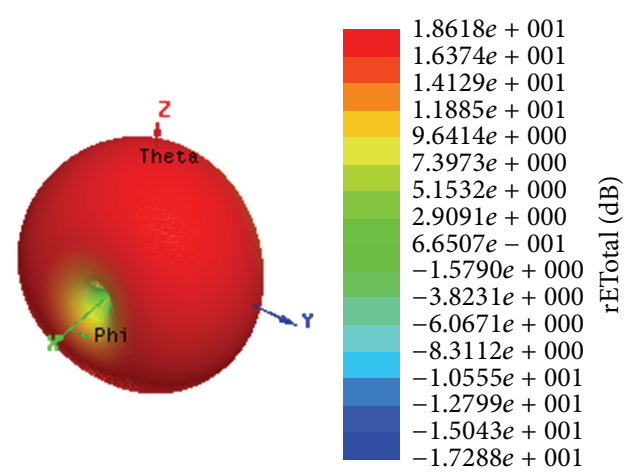

FIGURE 7: Simulated 3D radiation pattern plot for $6 \mathrm{GHz}$.

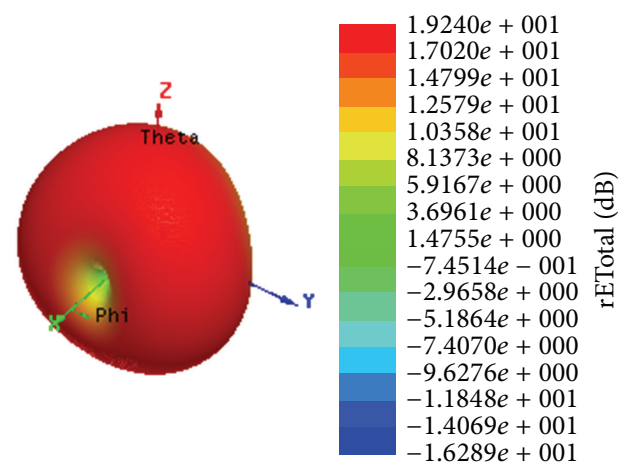

FIGURE 8: Simulated 3D radiation pattern plot for $8 \mathrm{GHz}$.

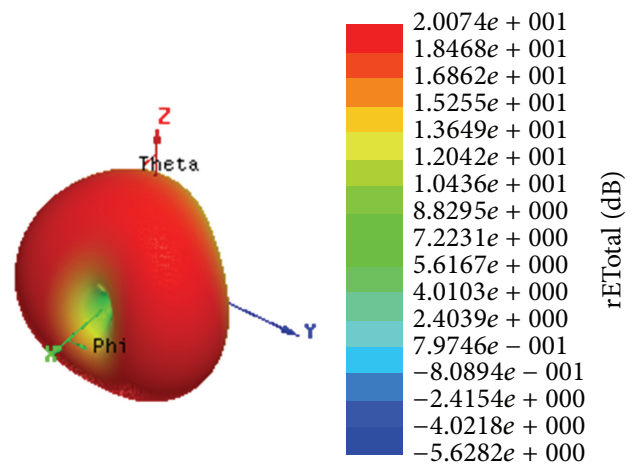

FIGURE 9: Simulated 3D radiation pattern plot for $10 \mathrm{GHz}$.

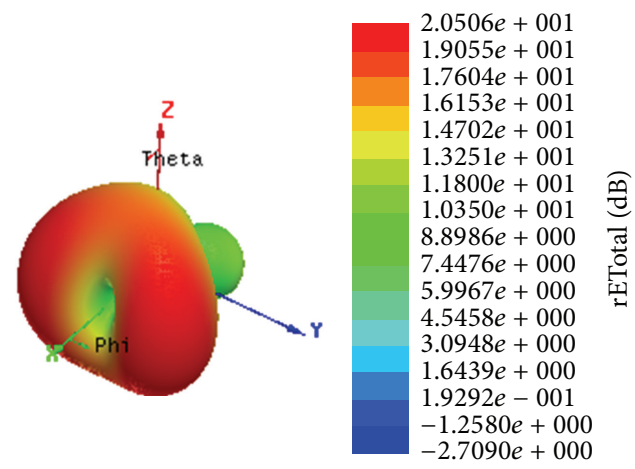

Figure 10: Simulated 3D radiation pattern plot for $12 \mathrm{GHz}$. 


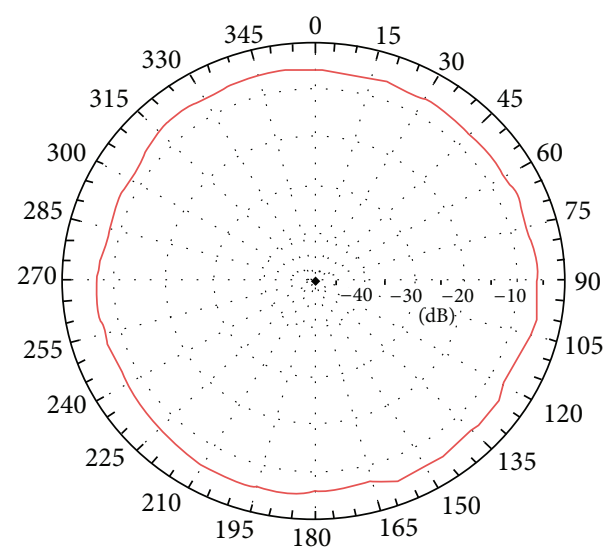

FIgURE 11: Horizontal cut of 3D measured radiation pattern at $8 \mathrm{GHz}$.

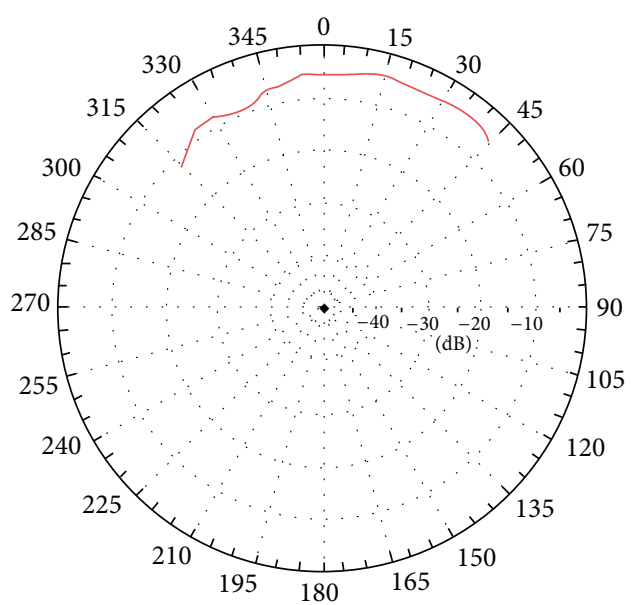

FIGURE 12: Vertical cut of 3D measured radiation pattern at $8 \mathrm{GHz}$.

TABLE 2: Antenna parameters comparison.

\begin{tabular}{lcc}
\hline Parameters & Simulated & Measured \\
\hline$S_{11}(\mathrm{~dB})$ & -17 & -19.4 \\
VSWR & 1.33 & 1.24 \\
Impedance bandwidth $(\mathrm{GHz})$ & 7.6 & 7 \\
Peak gain $(\mathrm{dB})$ & 5.6 & 5.2 \\
Peak directivity $(\mathrm{dB})$ & 5.75 & 5.3 \\
Radiation efficiency (\%) & 97.4 & 98 \\
\hline
\end{tabular}

Radiation pattern measurements are made with antenna oriented vertically in anechoic chamber. Horizontal cut of measured radiation pattern of Figure 11 shows omnidirectional behaviour. Vertical cut of measured radiation pattern shows doughnut beam width from 45 to 315 degrees in anticlockwise direction. Figures 11 and 12 normalized plots show high radiated electric field values. This gives a long range of antenna coverage field.

Measured 3D radiation pattern verifies that omnidirectional behaviour is depicted from horizontal and vertical cuts. Doughnut shape is fairly smooth. Omnidirectional radiation

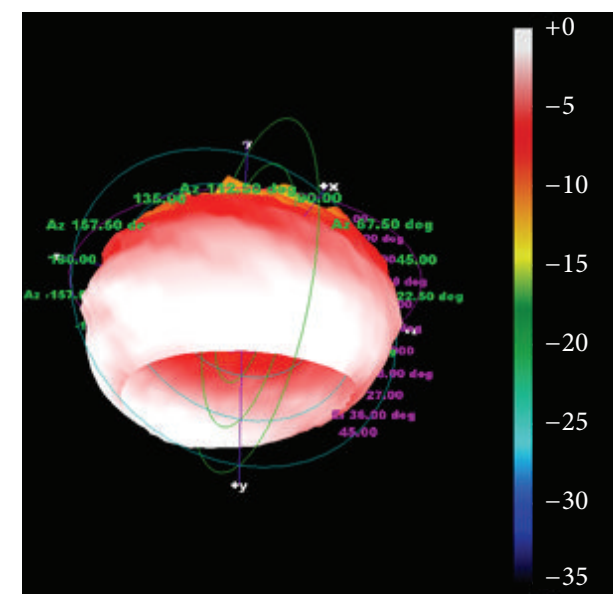

Figure 13: 3D measured radiation pattern at $8 \mathrm{GHz}$.

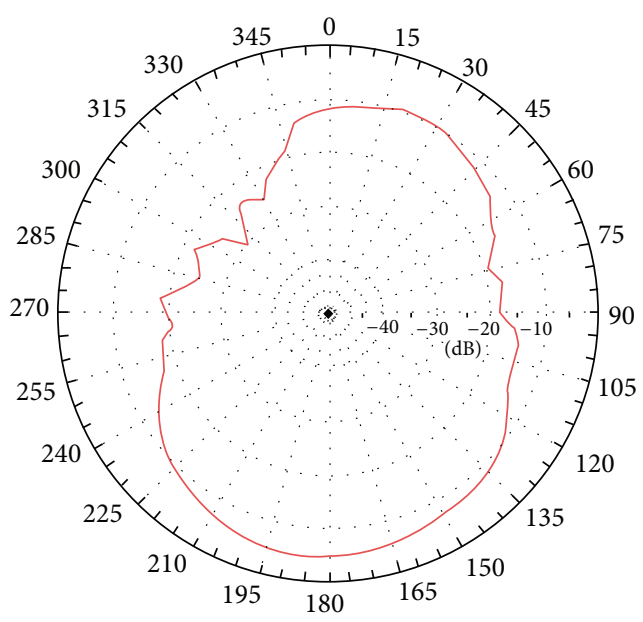

FIgURE 14: Horizontal cut of 3D measured radiation pattern at $10 \mathrm{GHz}$.

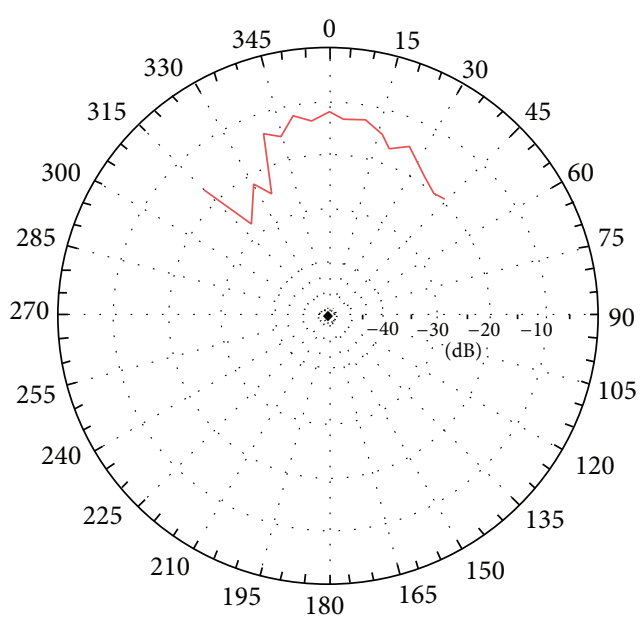

FIGURE 15: Vertical cut of 3D measured radiation pattern at $10 \mathrm{GHz}$. 
TABLE 3: Comparison with conventional antennas.

\begin{tabular}{|c|c|c|c|c|}
\hline Antenna & $\begin{array}{c}\text { Impedance } \\
\text { bandwidth }(\mathrm{GHz})\end{array}$ & Peak gain $(\mathrm{dBi})$ & Antenna size & Substrate \\
\hline Notch UWB antenna [24] & $\begin{array}{c}6.5 \text { (without notch) } \\
1.4 \text { (with notch) }\end{array}$ & 3 & $16 \times 22 \mathrm{~mm}^{2}$ & $\begin{array}{c}\text { Rogers } \\
\text { RO4003 }\end{array}$ \\
\hline Miniaturized UWB monopole [25] & 11.5 & 4.4 & $20 \times 25 \mathrm{~mm}^{2}$ & FR4 \\
\hline Square octal fractal [26] & 11.42 & 4.18 & $\begin{array}{c}83 \times 41.5 \mathrm{~mm}^{2} \\
(\mathrm{CPW} \text { and side ground } \\
\text { size only) }\end{array}$ & FR4 \\
\hline Proposed UWB monopole antenna & 7 & 5.2 & $20 \times 25 \mathrm{~mm}^{2}$ & FR4 \\
\hline
\end{tabular}

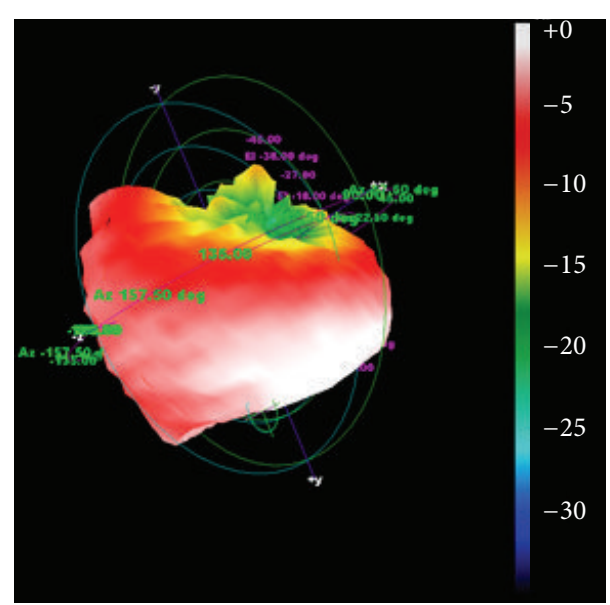

FIGURE 16: 3D measured radiation pattern at $10 \mathrm{GHz}$.

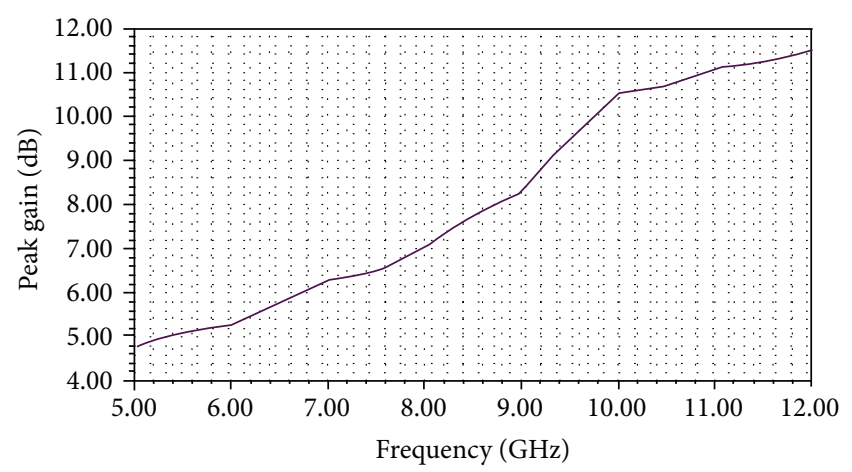

FIGURE 17: Measured Peak gain versus frequency plot.

pattern is characteristic of monopole antenna. This feature is depicted in radiation patterns of proposed monopole fractal antenna. Horizontal, vertical cuts, and 3D plots of measured radiation pattern for frequency of $10 \mathrm{GHz}$ are shown in Figures 14, 15, and 16, respectively.

Horizontal and vertical cuts of Figures 14 and 15 depict a smooth doughnut shaped radiation pattern. Beam width has reduced. Radiated electric field doughnut is tilted but antenna still remains omnidirectional. Simulated and measured 3D radiation pattern of Figures 10 and 16 show that electric field doughnut is shifting from vertical $y z$-plane to positive $x$-axis. This can be seen in radiation patterns both simulated and measured ones. Figures 13 and 14 show that radiation pattern still remains omnidirectional. Three dimensional radiation pattern plots show that at lower end of frequencies in antenna band, radiation pattern or main doughnut of electric field is located along $y z$-plane according to antenna orientation of Figure 3. Measured radiation pattern plots show that prototype antenna have omnidirectional radiation property.

Peak gain versus frequency plot is given in Figure 17. Omnidirectional monopole UWB fractal antenna has higher gain as compared to the conventional UWB monopole antennas.

Table 2 shows comparison between simulated and measured antenna parameter values. Antenna shows satisfactory performance.

Wideband impedance matching shows that return loss values are below $-19.4 \mathrm{~dB}$. This results in high power transfer which is eventually radiated. Radiation efficiency of 98 percent shows minimal radiation losses with $5.2 \mathrm{~dB}$ gain which shows that antenna can be used for wide coverage area. A comparison between proposed antenna and other important works in the field of UWB antennas is done in Table 3. Proposed antenna appears to be ultrawideband, compact, low cost, and has higher gain. These parameters can be observed in Table 3.

Possible application areas in these frequency ranges fall in $\mathrm{C}$ and $\mathrm{X}$ bands. Prototype antenna can easily be integrated into many applications due to its low profile and compactness.

\section{Conclusions}

Ultrawideband heptagonal fractal monopole antenna with CPW feed is designed and fabricated. Proposed antenna demonstrated that UWB antennas can be efficiently designed using fractal techniques. CPW feeding technique provides wideband impedance matching required for UWB antennas. Increase in bandwidth is also observed by increasing iterations of concentric arrays. Peak impedance bandwidth of $7 \mathrm{GHz}$ and peak gain of $5.2 \mathrm{~dB}$ with 98 percent radiation efficiency are achieved. Compactness of UWB antenna is achieved by the use of iterative concentric arrays. Proposed fractal antenna is a cost effective solution for body area networks because of its use with low cost FR4 substrate as compared to other high frequency substrates. UWB fractal antenna can be installed anywhere on the body of patient for remote monitoring as the antenna has omnidirectional 
radiation pattern. Moreover, the monopole fractal antenna can also be used in $\mathrm{C}$ and $\mathrm{X}$ band applications.

\section{Conflict of Interests}

The authors declare that there is no conflict of interests regarding the publication of this paper.

\section{References}

[1] I. Sarkar, P. P. Sarkar, and S. K. Chowdhury, "A new compact printed antenna for mobile communication," in Proceedings of the Loughborough Antennas and Propagation Conference (LAPC '09), pp. 109-112, November 2009.

[2] S. Chatterjee, U. Chakraborty, I. Sarkar, P. P. Sarkar, and S. K. Chowdhury, "A compact microstrip antenna for mobile communication," in Proceedings of the Annual IEEE India Conference: Green Energy, Computing and Communication (INDICON '10), December 2010.

[3] U. Chakraborty, S. Chatterjee, S. K. Chowdhury, and P. P. Sarkar, "A comact microstrip patch antenna for wireless communication," Progress in Electromagnetics Research C, vol. 18, pp. 211220, 2011.

[4] W. J. Krzysztofik and J. Jedrzejczak, "The challenge of miniaturization of the handset antennas of mobile communication systems," in Proceedings of the National Conference Radio communications, Radio, Broadcasting and Television, pp. 221224, Kraków, Poland, 2005.

[5] K. J. Vinoy, J. K. Abraham, and V. K. Varadan, "On the relationship between fractal dimension and the performance of multi-resonant dipole antennas using Koch curves," IEEE Transactions on Antennas and Propagation, vol. 51, no. 9, pp. 2296-2303, 2003.

[6] B. B. Mandelbrot, The Fractal Geometry of Nature, Freeman, New York, NY, USA, 1983.

[7] L. Ying, G. Shu-Xi, and F. De-Min, "Microstrip fractal patch antenna for multi-band communication," in Proceedings of the 23rd International Conference on Microwave and Millimeter Wave Technology, pp. 600-602, 2002.

[8] J. Guterman, A. A. Moreira, and C. Peixeiro, "Microstrip fractal antennas for multistandard terminals," IEEE Antennas and Wireless Propagation Letters, vol. 3, no. 1, pp. 351-354, 2004.

[9] M. R. Haji-Hashemi, H. M.-M. Sadeghi, and V. M. Moghtadal, "Space-filling patch antennas with CPW feed," in Proceedings of the Progress in Electromagnetic Research Symposium, vol. 2, pp. 69-73, March 2006.

[10] D. H. Werner and S. Ganguly, "An overview of fractal antenna engineering research," IEEE Antennas and Propagation Magazine, vol. 45, no. 1, pp. 38-57, 2003.

[11] B. Manimegalai, S. Raju, and V. Abhaikumar, "A multifractal Cantor antenna for multiband wireless applications," IEEE Antennas and Wireless Propagation Letters, vol. 8, pp. 359-362, 2009.

[12] J. Pourahmadazar, C. Ghobadi, J. Nourinia, and H. Shirzad, "Multiband ring fractal monopole antenna for mobile devices," IEEE Antennas and Wireless Propagation Letters, vol. 9, pp. 863866, 2010.

[13] M. Naghshvarian-Jahromi, "Novel wideband planar fractal monopole antenna," IEEE Transactions on Antennas and Propagation, vol. 56, no. 12, pp. 3844-3849, 2008.
[14] R. Li, B. Pan, J. Laskar, and M. M. Tentzeris, "A novel lowprofile broadband dual-frequency planar antenna for wireless handsets," IEEE Transactions on Antennas and Propagation, vol. 56, no. 4, pp. 1155-1162, 2008.

[15] C. P. Baliarda, C. B. Borau, M. N. Rodero, and J. R. Robert, "An iterative model for fractal antennas: application to the Sierpinski gasket antenna," IEEE Transactions on Antennas and Propagation, vol. 48, no. 5, pp. 713-719, 2000.

[16] K. Shambavi and Z. C. Alex, "Design of printed multistrip monopole antenna for UWB applications," Microwave and Optical Technology Letters, vol. 53, no. 8, pp. 1750-1752, 2011.

[17] E. Lule, T. Babij, and T. Derivative, "Koch island fractal ultra wideband dipole antenna," in Proceedings of the IEEE Antennas and Propagation Society International Symposium, vol. 3, pp. 2516-2519, 2004.

[18] N. P. Agrawall, G. Kumar, and K. P. Ray, "Wide-band planar monopole antennas," IEEE Transactions on Antennas and Propagation, vol. 46, no. 2, pp. 294-295, 1998.

[19] L. Yang and G. B. Giamalkis, "Ultra wide band communications," IEEE Signal Processing Magazine, pp. 26-54, 2004.

[20] K. H. Sayidmarie and Y. A. Fadhel, "UWB fractal monopoles of rectangular and triangular shapes," in Proceedings of the 4th IEEE International Symposium on Microwave, Antenna, Propagation and EMC Technologies for Wireless Communications (MAPE '11), pp. 709-712, November 2011.

[21] A. A. Lotfi-Neyestanak, M. R. Azadi, and A. EmamiForooshani, "Compact size ultra wideband hexagonal fractal antenna," in Proceedings of the 25th Queen's Biennial Symposium on Communications (QBSC '10), pp. 387-390, May 2010.

[22] A. Azari, "A new super wideband fractal microstrip antenna," IEEE Transactions on Antennas and Propagation, vol. 59, no. 5, pp. 1724-1727, 2011.

[23] D. H. Werner, R. L. Haupt, and P. L. Werner, "Fractal antenna engineering: the theory and design of fractal antenna arrays," IEEE Antennas and Propagation Magazine, vol. 41, no. 5, pp. 3759, 1999.

[24] A. Falahati, M. Naghshvarian-Jahromi, and R. M. Edwards, "Dual band-notch CPW-ground-fed UWB antenna by fractal binary tree slot," in Proceedings of the 5th International Conference on Wireless and Mobile Communications (ICWMC '09), pp. 385-390, August 2009.

[25] H. Oraizi and S. Hedayati, "Miniaturized UWB monopole microstrip antenna design by the combination of Giusepe Peano and Sierpinski carpet fractals," IEEE Antennas and Wireless Propagation Letters, vol. 10, pp. 67-70, 2011.

[26] R. Kumar, J. P. Shinde, P. N. Shinde, and M. D. Uplane, "On the design of CPW-fed square octal shaped fractal UWB antenna," in Proceedings of the Applied Electromagnetics Conference (AEMC '09), December 2009. 

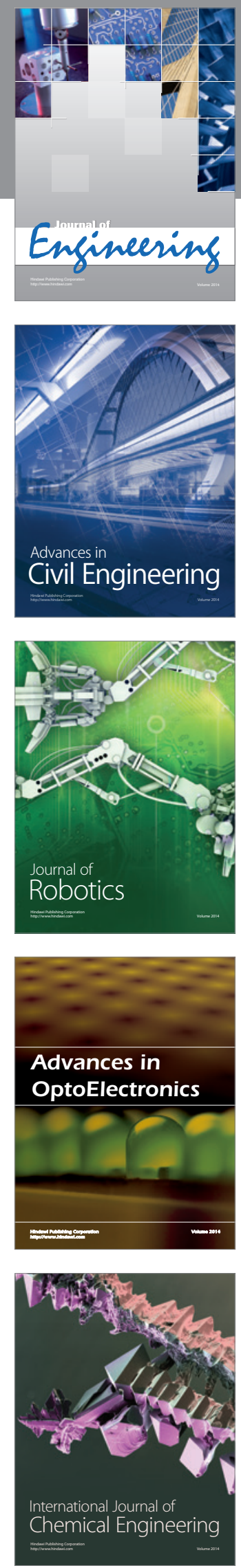

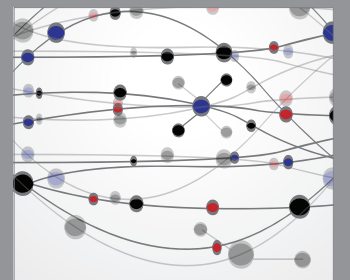

The Scientific World Journal
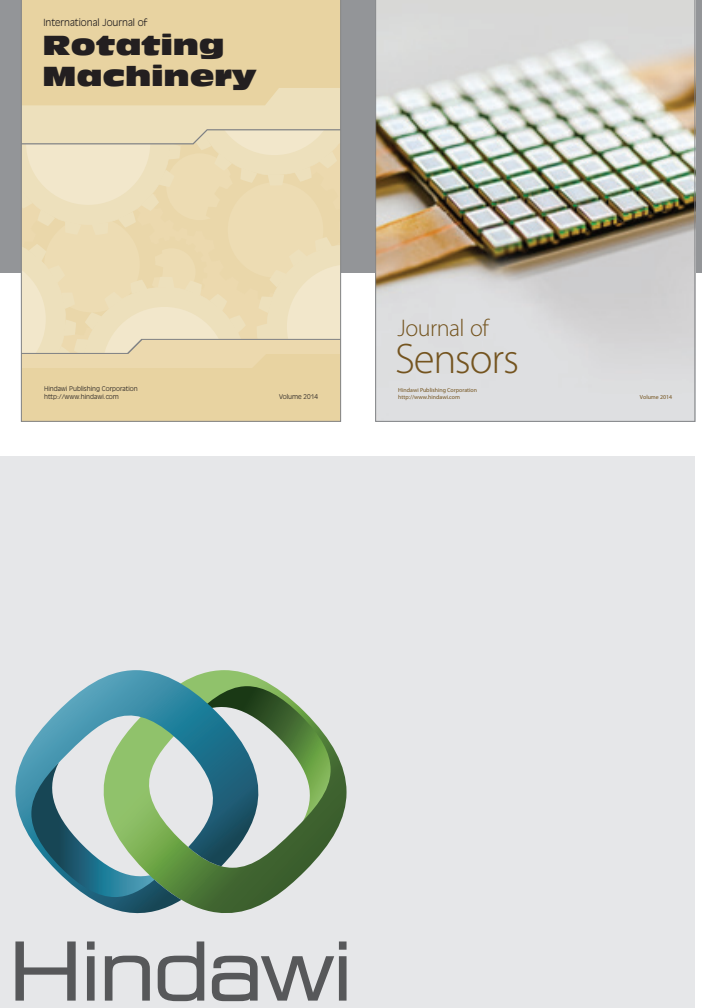

Submit your manuscripts at http://www.hindawi.com
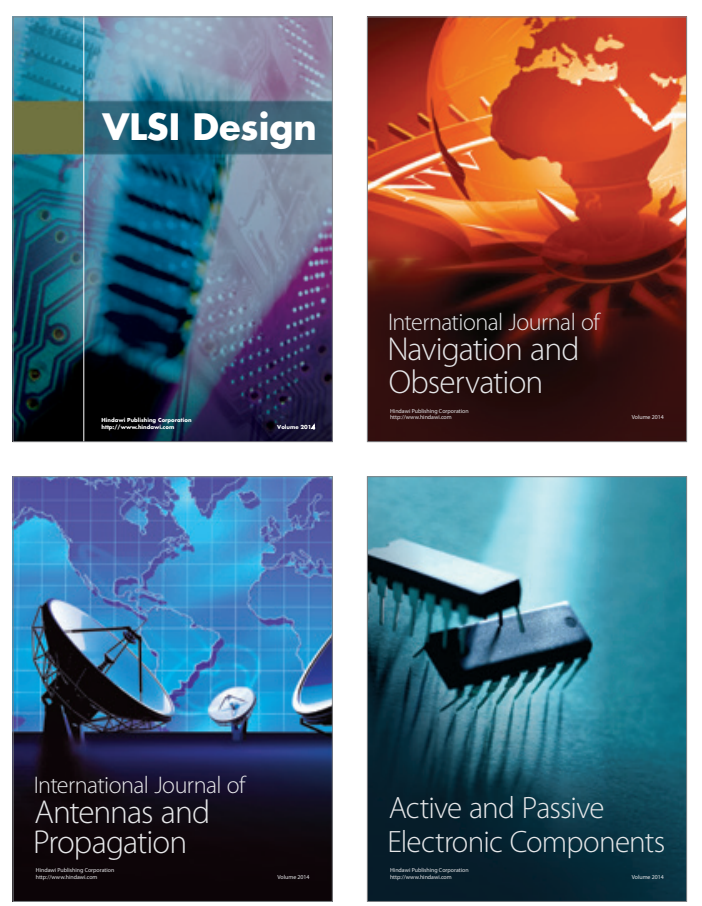
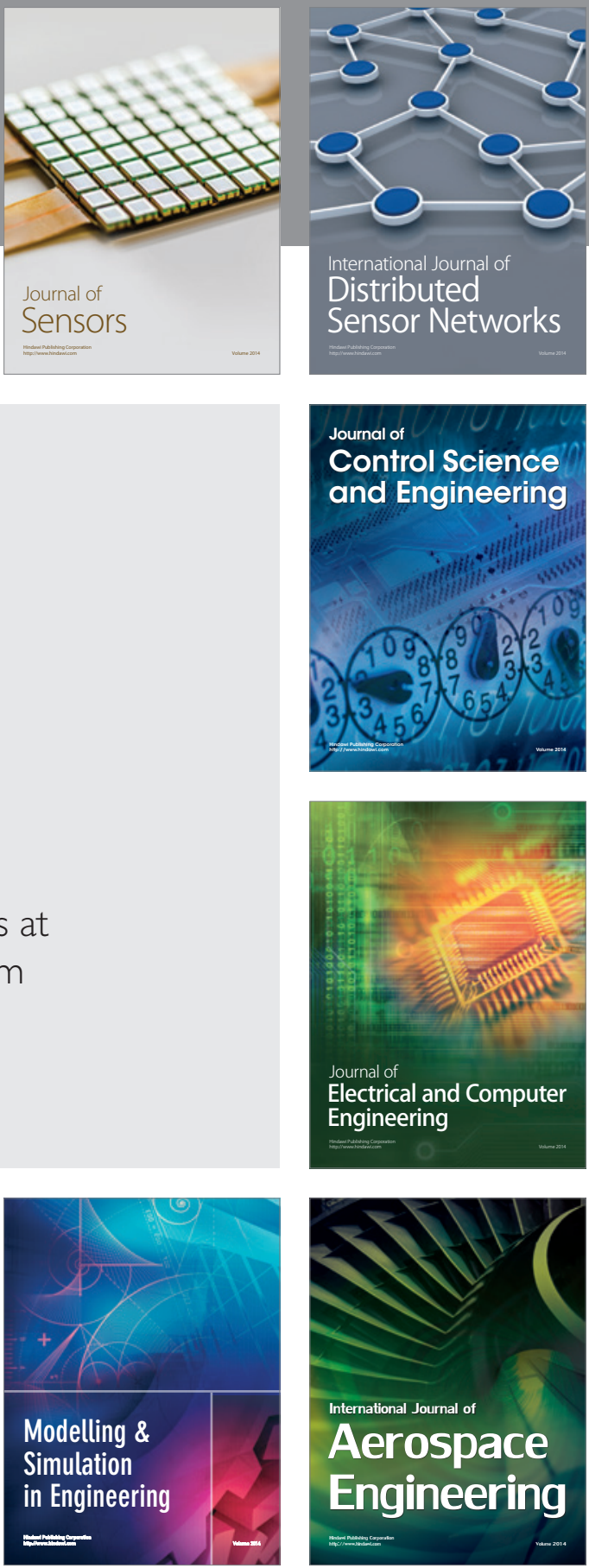

Journal of

Control Science

and Engineering
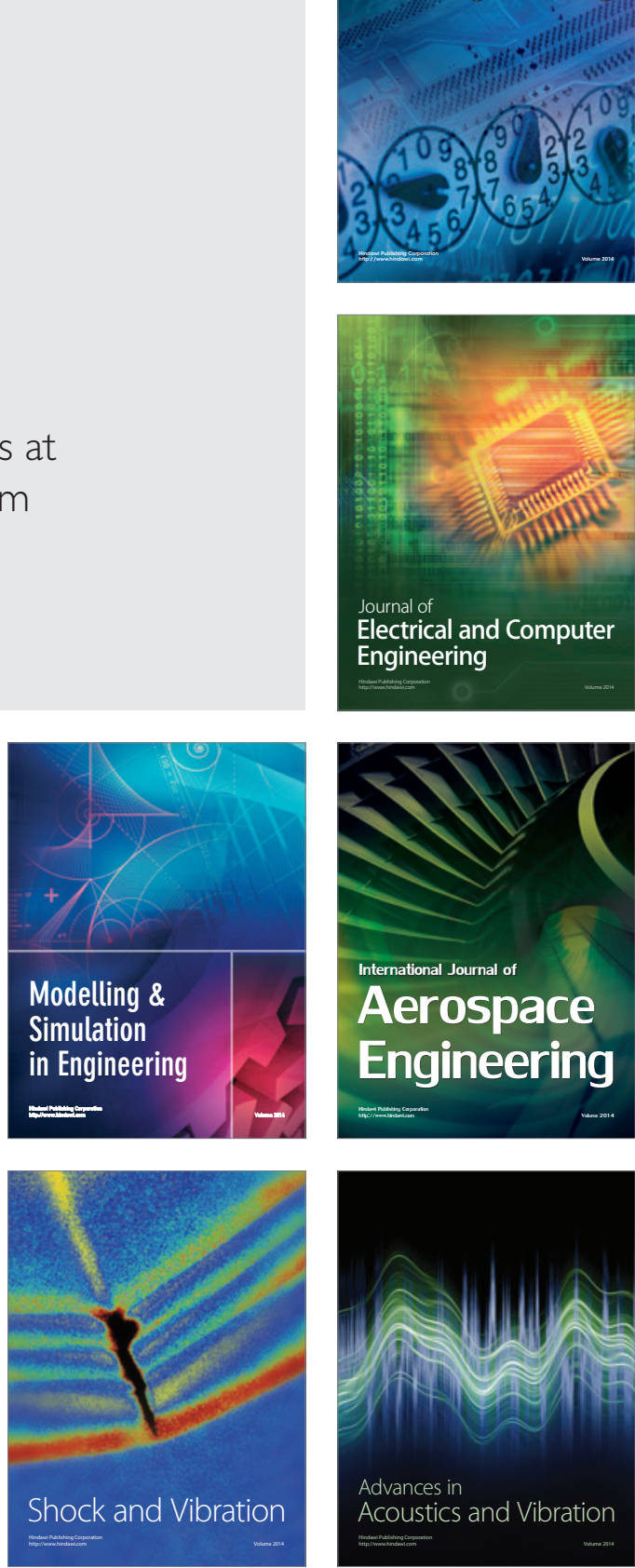